\title{
A Case Report: Unusual Presentation of a Common Disease
}

\author{
Muhammed $\mathrm{AS}^{1}$, Aye $\mathrm{M}^{2 *}$, Harshad $\mathrm{R}^{3}$ and Malik $\mathrm{KK}^{4}$ \\ ${ }^{1}$ Department of surgery, Melaka General Hospital, Malaysia \\ ${ }^{2}$ Department of Medicine, Melaka Manipal Medical College, Malaysia \\ ${ }^{3}$ Medical student of Melaka Manipal Medical College, Malaysia \\ ${ }^{4}$ Department of Surgery, Melaka Manipal Medical College, Malaysia
}

*Corresponding author: Aye M, Department of Medicine, Melaka Manipal Medical College, Malaysia

\begin{tabular}{|c|c|}
\hline ARTICLE INFO & ABSTRACT \\
\hline Received: 㐩 June 19, 2019 & Appendicitis is a common disease. However, tip appendicitis is found in $4-5 \%$ of all \\
\hline Published: 业 June 28, 2019 & $\begin{array}{l}\text { appendicitis. Tip appendicitis, complicated by internal herniation of caecum with small } \\
\text { intestine resulting in small loop obstruction of small intestine, is more rare condition. }\end{array}$ \\
\hline
\end{tabular}

Citation: Muhammed AS, Aye M, Harshad R, Malik KK. A Case Report: Unusual Presentation of a Common Disease. Biomed J Sci \& Tech Res 19(2)-2019. BJSTR. MS.ID.003272.

\section{Background}

The diagnosis of acute appendicitis is mainly clinical, and presentation of acute appendicitis may be typical or atypical. Typical presentation starts with vague peri-umbilical pain for several hours, which later migrates to the right iliac fossa (RIF), associated with lack of appetite, nausea or vomiting. Atypical histories may include pain in the right lower quadrant as an initial symptom [1].

Acute Appendicitis with Atypical Presentation: retrocecal location, malrotation by situs inversus, appendix with inguinal hernia, tip appendicitis, stump appendicitis and intraluminal appendiceal air.

Appendicular Abnormalities Simulating Acute Appendicitis: appendicular dilatation, appendicular diverticulitis, appendicular inflammation by contiguity, tumors and mucocele.

Distal appendicitis is the obstruction of the vermiform appendix frequently caused by an fecalith which may be located at any segment of the appendix. Because of this, a small percentage of cases show an obstruction at the level of the tip with the consequent initial inflammation of only just a small segment distal to the obstruction at a relative distance from the base and, the typical findings, such as the inflammatory involvement of the cecum, could be absent and the more insidious clinical symptoms make diagnoses more difficult. The typical MDCT (Multidetector Computed Tomography) findings in acute appendicitis are appendicular dilatation, increased wall thickness, signs of peri-appendicular inflammation and the presence of an faecolith [2].

\section{Loss of the echogenic mucosal stripe reflects}

a. Ischemic ulceration,

b. Loculated periappendiceal fluid is virtually diagnostic of perforated appendicitis,

c. Mural hyperemia on color Doppler indicates inflammation; mural pneumatosis and lack of color Doppler flow are seen with gangrenous appendicitis,

d. Increased periappendiceal and pericecal echogenicity is related to mesenteric and/or omental inflammation,

e. Periappendiceal fluid, mesenteric adenopathy and a dynamic small bowel are less specific ultrasound findings [3]. 
Ultrasound and CT findings of tip appendicitis may not accurately associate with a final diagnosis of acute appendicitis. Clinical judgment should ultimately dictate appropriate initial management, follow-up tests, and imaging [4,5]. Although rare, acute tip (or distal) appendicitis is more frequently diagnosed following the widespread adoption of CT imaging. Tip appendicitis does not carry the same degree of morbidity but is, nevertheless, an important diagnosis to make to avoid complications [6]. It has unclear pathophysiology, same degree of morbidity as inflammation of the entire appendix and close attention to all portions of appendix from its origin to the distal portion [7].

\section{Case in Detail}

A 59-year-old man chronic heavy smoker diagnosed with diabetes and hypertension for 7 years was admitted for first episode of progressive acute abdominal pain for one day. The pain was generalized and colicky in nature and radiated to the back. The pain score was $4 / 10$. It was associated with nausea and vomiting for 10 times which was non- projectile and bilious in nature, abdominal distension and in ability to pass stool and flatus. Otherwise, there were no other gastrointestinal and hepatobiliary symptoms. No past history of abdominal surgery, colonoscopy, chronic constipation and frequent episodes of right lower quadrant abdominal pain. On examination, he was alert, conscious, co- operative and comfortable. His blood pressure was $166 / 87 \mathrm{mmHg}$, pulse rate 96 beats per minute and other vital signs were normal. Abdominal examination revealed a localized abdominal distension in the right hypochondrium region. Palpation revealed a tender vague mass in the right hypochondrium extending to the epigastric region. Rebound tenderness was not elicited. Bowel sounds were intact. Another systems examination was normal. Digital per rectal examination was normal.

Urgent plain X-ray abdomen showed an inverted coffee bean sign / embryo sign of caecal volvulus and the apex is pointing towards the left upper quadrant of abdomen, caecal dilatation, single air-fluid level, small bowel dilatation and absence of gas in distal colon (Figure 1). His random plasma glucose was $19 \mathrm{mmol} / \mathrm{L}$, $\mathrm{SpO}_{2}$ 99\% under room air. Full blood count: hemoglobin $12.1 \mathrm{~g} / \mathrm{dl}$, total white count of $199 \times 10^{9} / \mathrm{L}$, platelet count of $398 \times 10^{9} / \mathrm{L}$. Renal profile: Urea $7.2 \mathrm{mmol} / \mathrm{L}$, Creatinine $104 \mathrm{u} \mathrm{mol} / \mathrm{L}, \mathrm{Na} 128 \mathrm{mmol} / \mathrm{L}$, $\mathrm{Cl}^{-} 97 \mathrm{mmol} / \mathrm{L}, \mathrm{K}^{+} 3.5 \mathrm{mmol} / \mathrm{L}$, eGFR $63.4 \mathrm{~mL} / \mathrm{min} / 1.73 \mathrm{~m}^{2}$. Liver function test: total protein $52 \mathrm{~g} / \mathrm{L}$, albumin $25 \mathrm{~g} / \mathrm{L}$, globulin 27 g/L, total bilirubin $6.4 \mathrm{u} \mathrm{mol} / \mathrm{L}$, Alanine Transferase (ALT) $9 \mathrm{U} / \mathrm{L}$, Aspartate amino transferase (AST) 20, Alkaline phosphatase (ALP) $105 \mathrm{U} / \mathrm{L}$. Coagulation profile: prothrombin time: $11.5 \mathrm{sec}$, INR 1.03 and APTT Ratio was 0.87 . His serumCa ${ }^{2+}: 1.82 \mathrm{mmol} / \mathrm{L}$, inorganic Phosphate $0.83 \mathrm{mmol} / \mathrm{L}$. His Creatine Kinase (CK) 313, lactate 1.5 mmol/L and amylase $208 \mathrm{U} / \mathrm{L}$ (Figure 1).

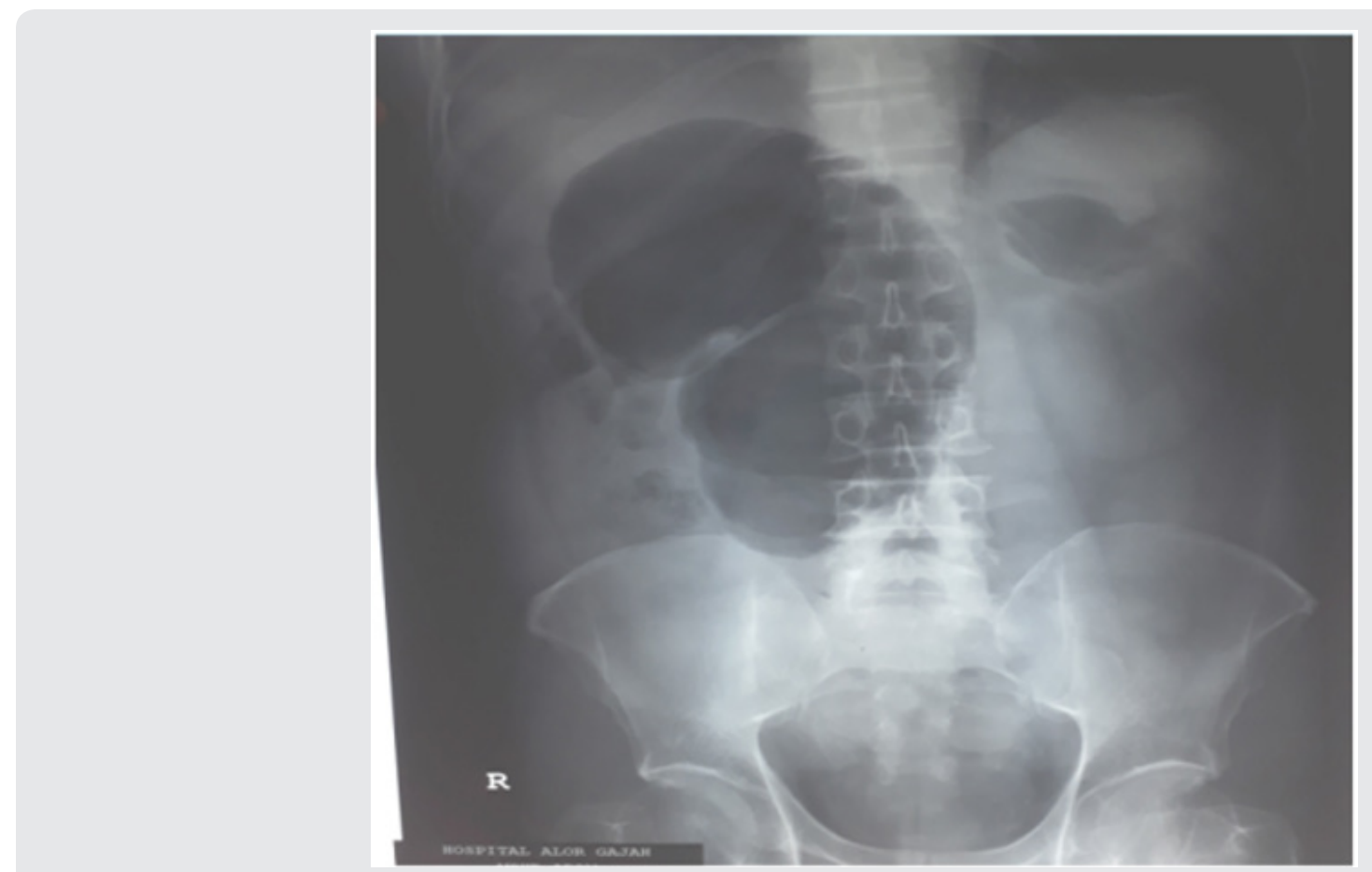

Figure 1: Plain $\mathrm{X}$ ray abdomen.

A diagnosis of Intestinal obstruction due to ceacal volvulus was made and initial treatment of decompression colonoscopy, nil per oral and intravenous Hartmann solution one pint over onehour, intravenous Ceftriaxone and Metronidazole were given and plain X-ray abdomen was requested. Intake /output chart was maintained. a) Plain X-ray abdomen report was: A dilated bowel loop in the right side of abdomen likely to represent volvulus. There was devoid of bowel contents in the left side of abdomen.

b) Impression: Features are in keeping with volvulus with underlying intestinal obstruction suggested CT abdomen for further evaluation. 
Colonoscopy and colonoscopy decompression were done about 8 hours after the admission. It was scoped until ascending colon. It was unable to visualise ceacum because of faeces, twisted part is noted at $38 \mathrm{~cm}$ from anal valve. After the twisted part there was a hugely dilated bowel which has normal mucosa with healthy looking and no bleeding (Figure 2).

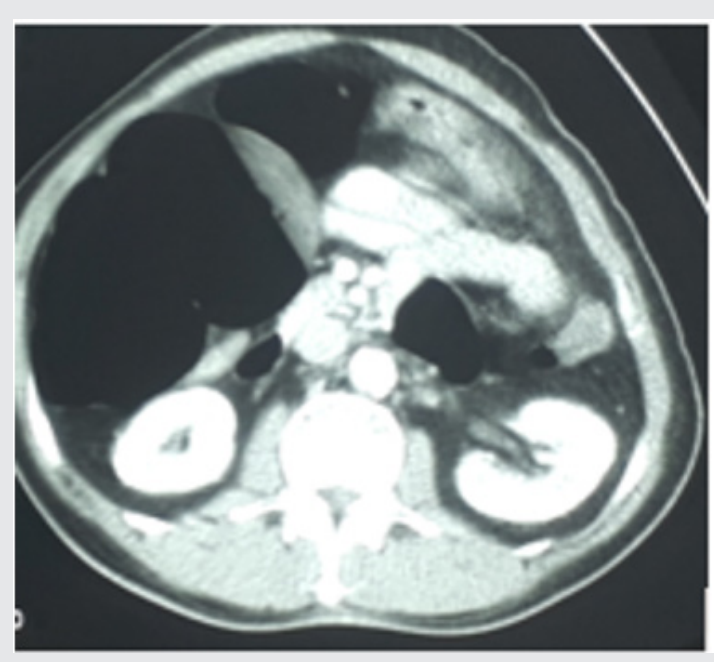

Figure 2: CT scan of abdomen.

About 7 hours later proceeded with CT abdomen (Computer tomography) of abdomen. It showed a rectal tube in the rectosigmoid colon. There is short segment focal dilatation of the ascending colon with a maximum diameter of $9.4 \mathrm{~cm}$. The wall of the affected colonic segment is not thickened. No intramural air or pneumotoses colon. The rest of the small or large bowel loops are not dilated. No 'whirl signs' of the mesentery seen. No bowel related mass. No pneumoperitoneum. No ascites. The descending colon appears displaced to the centre of the abdomen. Appendix is normal in appearance. No obvious filling defects seen in the mesenteric arteries.

a) Impression: History of recent distortion of sigmoid colon prior to CT scan. CT Abdomen shows focal dilatation of the ascending colon with no evidence of bowel edema or pneumoperitoneum. No bowel related mass to suggest bowel malignancy.

Emergency laparotomy was carried out 22 hours after the admission. Intra operative findings included apparently long appendix with tip adhesion to mesentery of small bowel causing internal herniation of ceacum within the loop and leads to closed loop obstruction of ileum and ceacum. Minimal adhesion of ceacum to anterior abdominal wall. (this sounds like appendicitis). Appendectomy was done.

\section{HPE Report}

Specimen consists of a congested appendix measuring $75 \times 8$ $\mathrm{x} 5 \mathrm{~mm}$ in diameter. Cut section shows empty lumen. Microscopic section shows focal mucosal ulceration with neutrophilic infiltration up to submucosa. In other areas, the mucosa appears degenerated with prominent congestion of blood vessels and haemorrhage. Fibrin deposition into vessel wall noted.

\section{Discussion}

The patient presented with symptoms of intestinal obstruction. Plain X-ray abdomen revealed a dilatation of localized segment of intestine looked like a shape of an embryo: caecal embro sign (Figure 1) and looks like one of the pictures of caecal volvulus (no.6) of radiology masterclass [8]. However, CT abdomen (ordinary CT) was neither in favour of caecal volvulus nor in favour of appendicitis in this case. Atypical presentation and plain X-ray features of caecal embryo sign mislead to caecal volvulus and management in such line was proceeded. When the abdominal pain was persisting, and laparotomy was carried out and found out to be tip appendicitis attached to the mesentery of small intestine making a hole through which caecum together with small intestine internally herniated resulting small loop obstruction. Juliana $M$ et al. [9] stated that when cecal volvulus is suspected, the absence of distal colonic decompression on CT topograms makes the diagnosis very unlikely. There is short segment focal dilatation of the ascending colon with a maximum diameter of $9.4 \mathrm{~cm}$ in this patient.

There is diagnostic challenges and pitfalls in diagnosis of acute appendicitis with atypical presentation. However, Ultrasound and MDCT have a high sensitivity and specificity for the diagnosis of acute appendicitis contributing to its correct diagnosis, especially in cases where the history and symptomatology are not the typical one. A meta-analysis Curtis et al. showed that, in children and adults, both ultrasound and MDCT have a high specificity (approximately 93-95\%) whereas the sensitivity of MDCT is higher compared with that of ultrasound (94\% versus $83-88 \%$, respectively) [2]. HK Lim et al reported that $85 \%$ had focal appendicitis that was correctly diagnosed at US. However, the entire length of the appendix should be evaluated to avoid a false-negative diagnosis [9]. However, the CT was not MDCT and Ultrasound was not requested. These might be the reasons that tip appendicitis was missed preoperatively. It has been reported that Ultrasound and CT findings of tip appendicitis may not accurately associate with a final diagnosis of acute appendicitis [4].

Haggi Mazeh et al. [11] studied the patients with the CT findings of tip appendicitis. This group of patients had a higher rate of right lower quadrant (RLQ) tenderness, leukocytosis and clinical suspicion for acute appendicitis ( $43 \%$ vs $0 \%$,) concluded that this group of patients can be managed conservatively in a subset of patients with low clinical suspicion for acute appendicitis. However, this patient needed laparotomy. It may be because of complication: internal herniation and small loop obstruction, which was not suspected pro- operatively, caecal volvulus instead. Therefore, retrospectively, we wonder whether plain X-ray abdomen features of caecal embro sign could be considered as small loop obstruction of intestine especially CT abdomen is not suggestive of caecal volvulus. However, small loop obstruction of intestine with such 
plain X- ray abdomen is not available in literature. It should learn from this case that small loop intestinal obstruction can have caecal embryo sign in plain X-ray abdomen. Further larger studies are necessary to support our proposal.

\section{Conclusion}

Caecal embryo sign is not diagnostic of caecal volvulus. Absence of distal colonic decompression on CT tomograms makes the diagnosis very unlikely of caecal volvulus. Appendicitis should be considered on top of acute pain in abdomen with vomiting.

\section{Acknowledgement}

We are thankful to hospital director of Melaka General Hospital for allowing to publish the case. We are also thankful to Prof Ava Tay and (Dept of Surgery of Melaka Manipla Medical College) for her expert opinion in the evaluation of the case.

\section{References}

1. Doherty GM (2010) In: Current Diagnosis and Treatment. Doherty GM, editor. New York: McGraw Hill pp. 615-620.

2. Mandich D, Chamorro E M, Ayala G (1995) Diagnostic challenges in acute appendicitis: atypical presentation and pitfalls. European Society of Radiology pp. 1-21.

\section{ISSN: 2574-1241}

DOI: $10.26717 /$ BJSTR.2019.19.003272

Aye M. Biomed J Sci \& Tech Res

(C) (P) This work is licensed under Creative

Submission Link: https://biomedres.us/submit-manuscript.php
3. Kessler N, Cyteval C, Gallix B, Lesnik A, Blayac PM, et al. (2004) Appendicitis: Evaluation of Sensitivity, Specificity, and Predictive Values of US, Doppler US, and Laboratory Findings. Radiology 230(2): 472-478.

4. Lim HK, Lee Wj, Lee SJ, Namgung S, Lim JH (1996) Focal appendicitis confined to the tip: diagnosis at US. Radiology 200(3): 799-80.

5. Leung B, Madhuripan N, Bittner K, Rastegar V, Banever G, et al. (2019) Clinical outcomes following identification of tip appendicitis on ultrasonography and CT scan. Journal of Pediatric Surgery 54(1): 108111.

6. Ebouda FM. Tip appendicitis. Radiopaedia.org.

7. Patlas MN, Bhalla S, Menias CO, Abdullah Alabousi, Douglas S. Katz (2015) Acute Appendicitis: Atypical Presentations and Mimics.

8. Lloyd G (2007) Radiology. Masterclass.

9. Juliana M Rosenblat, Alla M Rozenblit, Ellen L Wolf, Ronelle A DuBrow Elana I (2010) Den Findings of Cecal Volvulus at CT. Radiology 256(1)

10. H K Lim, W J Lee, S J Lee, S Namgung, J H Lim (2009) Focal appendicitis confined to the tip: Am J Surg. 197(2): 211-215.

11. Mazeh H, Epelboym I, Reinherz J, Greenstein AJ, Divino CM (2009) Tip appendicitis: clinical implications and management. Am J Surg 197(2):211-215.

$\begin{array}{ll}\text { BIOMEDICAL } & \text { Assets of Publishing with us } \\ \text { RESEARCHES } & \text { - Global archiving of articles } \\ & \text { - Immediate, unrestricted online access } \\ & \text { - Rigorous Peer Review Process } \\ \end{array}$

